\title{
Conservation genetics of bees: advances in the application of molecular tools to guide bee pollinator conservation
}

\author{
Margarita M. López-Uribe ${ }^{1}$ (I) $\cdot$ Antonella Soro $^{2} \cdot$ Shalene Jha $^{3}$
}

Received: 16 March 2017 / Accepted: 18 April 2017 / Published online: 27 April 2017

(C) Springer Science+Business Media Dordrecht 2017

Bees (Hymenoptera: Apoidea) are a monophyletic group of insects comprising an estimated 20,000 species distributed in a wide range of latitudes, including all terrestrial ecoregions except for Antarctica. One of the special characteristics of bees is that they are insects that exclusively use pollen and nectar to feed their brood-except for a handful of necrophagous stingless bee species (Roubik 1982). As a result of their dependence on floral resources, bees are the most important pollinators for the majority of flowering plant species (>80\%, Ollerton et al. 2011). The close interactions between bees and plants have shaped the deep evolutionary histories of bee families (Cardinal and Danforth 2013) and the demographic histories of bee species across natural, agricultural and urban landscapes (Dellicour et al. 2016; López-Uribe et al. 2016). In addition to managing bees for crop pollination, some bee species, including honey bees and stingless bees, have been used for centuries by humans for honey production (Crane 2013). An increasing number of bee species (e.g., Bombus terrestris, Megachile rotundata, Osmia cornifrons) are now being commercially produced for greenhouse and outdoor crop pollination in response to increases in the intensification of agricultural systems and related reductions in wild pollinator habitat (Aizen et al. 2009).

Margarita M. López-Uribe

mml64@psu.edu

1 Department of Entomology, Center for Pollinator Research, Pennsylvania State University, University Park, PA 16802, USA

2 Institute for Biology, Martin-Luther University Halle-Wittenberg, 06120 Halle (Saale), Germany

3 Department of Integrative Biology, The University of Texas at Austin, Austin, TX 78712, USA
As a result of habitat loss and a number of additional potential causes, populations of both managed and unmanaged bees have been reported to be declining during at least the last decade in different parts of the world (Biesmeijer et al. 2006; vanEngelsdorp and Meixner 2010; Cameron et al. 2011; Bartomeus et al. 2013). Because of their important role as key pollinators, the possibility of bee decline has raised concern about the potentially disastrous impacts of their loss on ecosystem functioning, which could affect multiple trophic levels and threaten food security for humans (Allen-Wardell et al. 1998; Potts et al. 2016). Thus, the decline of bee populations is of great conservation concern, and efforts from researchers, educators and policymakers are focusing on developing effective strategies to preserve and restore bee populations across habitats types (Brown and Paxton 2009; Dicks et al. 2013). However, the development of effective conservation strategies requires an understanding of key evolutionary and ecological processes, at both historic and contemporary time scales, such as the drivers of speciation, the generation and conservation of genetic variation and the factors influencing demography, colonization, migration and foraging (Frankham et al. 2004; Epps and Keyghobadi 2015).

Molecular tools can provide information relevant for a number of research themes underlying bee conservation, ranging from phylogeography and genetic variation across landscapes, to paternity assignment for colony-level foraging analyses (reviewed in Woodard et al. 2015). For example, phylogeographic studies are necessary to better understand bee diversity and to identify groups of conservation concern. These studies may be particularly relevant for the conservation of bee groups that have experienced high diversification rates, but exhibit little morphological differentiation or substantial convergent morphology (e.g. sweat bees or bumblebees, respectively). Determining 
how genetic variability is distributed across a species' geographic range is critical to identify units for conservation efforts (Duennes et al. 2012; López-Uribe et al. 2014; Dellicour et al. 2015).

Another important research theme in conservation genetics is understanding how landscape composition and topographic complexity drive population structure. Bees are flying insects and can often forage long distances, but it is unclear which habitat features influence their patterns of dispersal. Population genetic studies can shed light on potential drivers of dispersal from inferred genetic structure (Jha 2015). At contemporary time scales, reduced genetic diversity in a population can increase the risk of inbreeding (Zayed and Packer 2005), and inbreeding depression can result in fitness declines, such as slower growth rates and lower reproductive rates (Whitehorn et al. 2009). In bees and other haplodiploid insects with single locus complementary sex determination, the risk of inbreeding depression associated with the loss of genetic diversity is higher than in diploid organisms because sterile diploid males are produced if the sex determination locus is homozygous. Therefore, estimating levels of male diploidy can reveal genetic degradation at the population level and could assist in the identification of populations of conservation concern (Zayed and Packer 2005).

The study of relatedness within nesting aggregations and across landscapes is another important theme in conservation genetics. Specifically, examining bee relatedness across spatial scales can indicate the most important factors influencing dispersal and nest fidelity (López-Uribe et al. 2015), as well as the potential drivers of social behavior (Soro et al. 2010) and colony-level foraging patterns (Jha and Kremen 2013). Lastly, the availability of next generation sequencing (NGS) tools now allows for the development of research programs that identify adaptive variation in bee populations and the potential role of symbionts (e.g., microbes) in adaptive processes. Across these many research themes, conservation genetics information could be used to enhance breeding programs for managed bees, identify areas of great conservation value and improve habitat restoration programs for threatened species.

In order to update researchers on these themes, in August of 2015 we organized a symposium on the "Conservation Genetics of Bee Pollinators" at the Ecological Society of America Meeting in Baltimore, MD (USA). The outcomes of this symposium exceeded our expectations in synergy and breadth and provided the inspiration for this Special Issue of Conservation Genetics. Here, we present studies that use both traditional and novel genetic approaches to advance our understanding of (1) phylogeography: how geography and climate have shaped the evolutionary history of wild bee pollinators, (2) population structure, inbreeding and foraging: how the distribution of genetic diversity, ploidy and relatedness of individuals changes across landscapes, and (3) genetic consequences of bee management: how commercial bee management can influence patterns of genetic diversity and structure of key crop pollinators. These studies provide essential data for evidence-based recommendations regarding bee conservation and management strategies. Though this Special Issue is diverse and broad, it also highlights the critical need for additional studies on the genetic diversity of bees, the genetic structure of populations across space and the meaning of genetic diversity and structure for population demography and adaptation.

\section{Phylogeography}

Phylogeographic studies investigate spatial patterns of genetic diversity across large geographic scales to understand the role of geographic distance, topographic complexity and climate instability, among other potential factors, in mediating population connectivity. Koch et al. (2017) use a comparative approach to investigate levels of connectivity among four sympatric bumble bee (Bombus) species in the Pacific Northwest of the United States. They identify areas within the Pacific region that harbor isolated populations of the four bumble bee species and point out differences in ecological niches that may drive isolation by distance (IBD) patterns across sympatric species. Using coalescent approaches and Bayesian clustering methods, Cěrná et al. (2017) reconstruct the historical demography of two closely related species of Palearctic Anthophora bees. Their results show signatures of reduction in effective population size that coincide with increasing temperatures after glaciations, a result expected for cold-adapted species. Frantine-Silva et al. (2017) also provide insight on likely climate drivers of phylogeographic structure. Specifically, they analyze variability of mitochondrial genes in the neotropical orchid bee Euglossa iopoecila and find greater genetic diversity in central regions of the Atlantic forest (Brazil), where there was likely greater past climate stability, than in the southern regions, which exhibit signatures of recent population expansion. These results are consistent with the historical biogeography of other forest specialists in this ecoregion (Carnaval et al. 2009). In addition to exploring environmental drivers of phylogeographic structure using mitochondrial (COI) microsatellites, Duennes et al. (2017) add a morphometric analysis to their study of the Mesoamerican bumblebee B. ephippiatus. They find evidence of multiple evolutionarily significant lineages that are maintained by different geographic and environmental factors across the distribution of the species. Last, McKendrick et al. (2017) also investigate whether microsatellite nuclear markers support three cryptic species within the 
European bumblebee B. lucorum; indeed, they detect three discrete groups that correspond to three mtDNA lineages previously identified.

\section{Population structure, inbreeding and foraging}

Understanding how anthropogenic changes shift the distribution and levels of genetic diversity in bee populations may elucidate important demographic mechanisms associated with possible population decline. Lecocq et al. (2017) investigate IBD patterns of multiple social and solitary European bee species in a comparative individual-based versus population-based differentiation framework. Their results show that individual based approaches have the potential for greater detection power of IBD patterns and thus suggest a reassessment of the exclusive use of population-based analyses when investigating signatures of dispersal. Schenau and Jha (2017) examine genetic structure and diploidy in males of $B$. vosnesenskii across mainland and islands, including landscapes that exhibit a gradient of habitat quality (availability of flowers and nesting sites). Their findings indicate high levels of male diploidy, especially in the mainland and in areas with limited nesting habitat. Soro et al. (2017) also focus on male bees and examine patterns of genetic diversity and genetic structure in the males of two orchid bee species (E. dilemma and E. viridissima) across different levels of human disturbance and between mainland and islands. They find significantly reduced genetic diversity on islands, but no relationship between habitat loss and genetic diversity, though they do document low levels of both population structure and male diploidy. In another study of euglossine male bees, Suni (2017) likewise finds weak differentiation for $E$. imperialis across fragmented landscapes in Costa Rica, despite their dependence on forested habitat for nesting. Similarly, LandaverdeGonzalez et al. (2017) revealed very little genetic structure and no signatures of recent bottlenecks for the stingless bee Partamona bilineata in Guatemala. These three tropical bee studies and others (e.g., Jaffé et al. 2016) suggest that some species can be quite resilient to habitat degradation despite the high rates of fragmentation these regions are experiencing. At a finer spatial scale, one study in the Special Issue examines the relatedness and colony-identity among individuals across different floral resource landscapes. Pope and Jha (2017) develop a modeling approach to evaluate the efficacy of different sampling approaches to build molecular-based foraging clouds for social bees. They provide a quantitative comparison of the multiple sampling methods currently used by most scientists to map colonylevel foraging and then make recommendations for future mapping of spatial foraging analyses.

\section{Genetic consequences of bee management}

The process of animal domestication is associated with dramatic changes in the phenotype and genotype of domesticated species. While humans have bred some bee species for honey production and crop pollination, these are not considered domesticated species because they do not significantly differ from their wild ancestors. Understanding how bee management has changed the frequency and distribution of neutral and adaptive genetic diversity in bees is critical for the conservation of important genetic variability that can be used for breeding programs in these species. Using microsatellite data, López-Uribe et al. (2017) compare feral and managed honey bee (Apis mellifera) genetic diversity and find that it positively correlates with immune response in feral, but not managed colonies. This study highlights the importance of wild populations as sources of genetic variability for breeding programs aimed at supporting healthier managed species. In another comparative study, Suni et al. (2017) investigate the population structure of B. impatiens in natural and agricultural areas of the Northeastern region of the United States, where managed bumblebee colonies are used for cranberry pollination. Based on Bayesian clustering analyses, this study shows that individuals from wild and commercial colonies are genetically distinct and suggest that managed colonies may not be successfully establishing in the areas where they are introduced. In one of the first molecular studies of the solitary managed alfalfa leafcutting bee $M$. rotundata, Strange et al. (2017) use microsatellite-based population structure analyses to reveal that it exhibits low population structure in the introduced range, likely due to frequent movement by humans. Further, the authors found no signatures of a founder event after its introduction to North America, suggesting that genetic diversity is being maintained by breeding facilities in Canada before shipping to the southern US. While a number of bee species are bred for management, so far only the honey bee A. mellifera, has been subjected to breeding programs to select for specific traits (e.g., efficiency in pollination, resistance to pathogens). However, establishing breeding programs may be necessary for other managed bees in the near future. In a quantitative meta-analysis, Koffler et al. (2017) gathered published heritability estimates for ants, bees and wasps and found that they are influenced by trait type, with morphological traits exhibiting the highest heritability estimates, and defense and metabolism-related traits showing the lowest estimates of heritability. This study suggests that artificial selection for some traits may be feasible within pollinator breeding programs, even though further research is necessary. Among other important traits that may be considered for optimal commercial bee management programs is their association with microorganisms, an interaction that can 
often prove beneficial for bee health (reviewed in Engel et al. 2016). In this Special Issue, Graystock et al. (2017) examine the microbiota of two non-corbiculate bee species (genera Ceratina and Megalopta) and their relationship to pollen microbes. They report that, unlike A. mellifera, both species have similar microbiota that match their pollen provisions and only share one phylotype across all three bee species. They discuss their results in the context of the importance of considering healthy microbiomes for pollinator restoration projects.

\section{Closing remarks}

Even though we have made considerable progress in understanding the genetic factors that influence bee decline, the development of cost-effective high throughput sequencing technologies has opened new possibilities for the application of genomic approaches to conservation genetic questions in model and non-model bee species (Lozier 2014; Harpur et al. 2015). In the final piece of our Special Issue, Lozier and Zayed (2016) review this topic and discuss a conceptual framework for how different genomic tools can be applied to a wide range of important questions for bee conservation (Fig. 1, Lozier and Zayed 2016). Incorporating these new methods will greatly advance our knowledge and their application to enhancing conservation and restoration of wild and managed bee populations.

In summary, the field of bee conservation genetics has grown tremendously in the past decade since the first review of the field (Zayed 2009) and now spans an increasingly diverse set of research topics. This Special Issue highlights a number of key findings within these research themes. First, it reveals the importance of climate and geography in driving bee phylogeography. In particular, it highlights the role of climatic factors in current patterns of bee population structure. These results call attention to the potential impact of climate change on the stability of bee populations and species distribution. Conservation genetic studies that combine molecular data with climate niche models will continue to provide insights into predictions of population persistence and structure. A second important contribution of the studies in this special issue includes that tropical bee species are more resilient to anthropogenic change than traditionally expected. More case studies with a broader phylogenetic sampling are necessary to establish if this is a general pattern for all tropical bees, or if this finding is lineage specific and constrained to corbiculate bees of the wet forested Neotropics. Indeed, bees from temperate areas such as bumble bees seem to be much more dependent on habitat quality for enhanced nesting density, reduced inbreeding and lineage survival (Carvell et al. 2017). Last, a number of studies illustrate the promising role of genetics/genomics as a correlate for key traits useful for enhancing wild and commercial bee health. These studies highlight the need of conserve genetic diversity in wild bee populations and understanding its structure and function to design successful breeding programs.

Acknowledgements We would like to thank the participants of the Ecological Society of America 2015 Symposium titled "Conservation Genetics of Bee Pollinators" and all others for their contributions to this special issue. We also thank Jeff Lozier, Amro Zayed, and two anonymous reviewers for comments on this letter, as well as editors Rus Hoezel and Sean Hoban for their support. MML-U was funded by a National Science Foundation (NSF) Postdoctoral Fellowship (1523817). SJ received funding from the National Science Foundation, the UT-FAPESP grant, and the Army Research Office.

\section{References}

Aizen MA, Garibaldi LA, Cunningham SA, Klein AM (2009) How much does agriculture depend on pollinators? Lessons from long-term trends in crop production. Ann Bot 103:1579-1588. doi:10.1093/aob/mcp076

Allen-Wardell G, Bernhardt P, Bitner R et al (1998) The potential consequences of pollinator declines on the conservation of biodiversity and stability of food crop yields. Conservation Biology 12:8-17

Bartomeus I, Park MG, Gibbs J et al (2013) Biodiversity ensures plant-pollinator phenological synchrony against climate change. Ecol Lett 16:1331-1338. doi:10.1111/ele.12170

Biesmeijer JC, Roberts SPM, Reemer M et al (2006) Parallel declines in pollinators and insect-pollinated plants in Britain and the Netherlands. Science 313:351-354. doi:10.1126/ science. 1127863

Brown MJF, Paxton RJ (2009) The conservation of bees: a global perspective. Apidologie 40:410-416. doi:10.1051/apido/2009019

Cameron SA, Lozier JD, Strange JP et al (2011) Patterns of widespread decline in North American bumble bees. Proc Natl Acad Sci U S A 108:662-667. doi:10.1073/pnas.1014743108

Cardinal S, Danforth BN (2013) Bees diversified in the age of eudicots. Proc Biol Sci 280:20122686. doi:10.1098/rspb.2012.2686

Carnaval AC, Hickerson MJ, Haddad CF, Rodrigues MT, Moritz C (2009) Stability predicts genetic diversity in the Brazilian Atlantic forest hotspot. Science 323:785-789

Carvell C, Bourke AF, Dreier S, Freeman SN, Hulmes S, Jordan WC, Redhead JW, Sumner S, Wang J, Heard MS (2017) Bumblebee family lineage survival is enhanced in high-quality landscapes. Nature 543:547-549

Cĕrná K, Munclinger P, Vereecken NJ, Straka J (2017) Mediterranean lineage endemism, cold-adapted paleodemographic dynamics and recent changes in population size in two solitary bees of the genus Anthophora. Conserv Genet. doi:10.1007/ s10592-017-0952-8

Crane EE (2013) The world history of beekeeping and honey hunting. Routledge, London

Dellicour S, Michez D, Rasplus J-Y, Mardulyn P (2015) Impact of past climatic changes and resource availability on the population demography of three food-specialist bees. Mol Ecol 24:10741090. doi:10.1111/mec. 13085

Dellicour S, Kastally C, Varela S et al (2016) Ecological niche modelling and coalescent simulations to explore the recent geographical range history of five widespread bumblebee species in Europe. J Biogeogr. doi:10.1111/jbi.12748 
Dicks LV, Abrahams A, Atkinson J et al (2013) Identifying key knowledge needs for evidence-based conservation of wild insect pollinators: a collaborative cross-sectoral exercise. Insect Conserv Divers 6:435-446. doi:10.1111/j.1752-4598.2012.00221.x

Duennes MA, Lozier JD, Hines HM, Cameron SA (2012) Geographical patterns of genetic divergence in the widespread Mesoamerican bumble bee Bombus ephippiatus (Hymenoptera: Apidae). Mol Phylogenet Evol 64:219-231. doi:10.1016/j. ympev.2012.03.018

Duennes MA, Petranek C, de Bonilla EPD et al (2017) Population genetics and geometric morphometrics of the Bombus ephippiatus species complex with implications for its use as a commercial pollinator. Conserv Genet. doi:10.1007/s10592-016-0903-9

Engel P, Kwong WK, McFrederick Q, Anderson KE, Barribeau SM, Chandler JA et al (2016) The bee microbiome: impact on bee health and model for evolution and ecology of host-microbe interactions. Mbio 7:9

Epps CW, Keyghobadi N (2015) Landscape genetics in a changing world: disentangling historical and contemporary influences and inferring change. Mol Ecol 24:6021-6040. doi:10.1111/ mec. 13454

Frankham R, Ballou JD, Briscoe DA (2004) A primer of conservation genetics, illustrated, reprint. Cambridge University Press, Cambridge

Frantine-Silva W, Giangarelli DC, Penha RES et al (2017) Phylogeography and historical demography of the orchid bee Euglossa iopoecila: signs of vicariant events associated to quaternary climatic changes. Conserv Genet. doi:10.1007/s10592-016-0905-7

Graystock P, Rehan SM, McFrederick QS (2017) Hunting for healthy microbiomes: determining the core microbiomes of Ceratina, Megalopta, and Apis bees and how they associate with microbes in bee collected pollen. Conserv Genet. doi:10.1007/ s10592-017-0937-7

Harpur BA, Chapman NC, Krimus L, et al (2015) Assessing patterns of admixture and ancestry in Canadian honey bees. Insectes Soc 62:479-489. doi:10.1007/s00040-015-0427-1

Jaffe R, Castilla A, Pope N, Imperatriz-Fonseca VL, Metzger JP, Arias MC, Jha S (2016) Landscape genetics of a tropical rescue pollinator. Conserv Genet 17:267-278

Jha S (2015) Contemporary human-altered landscapes and oceanic barriers reduce bumble bee gene flow. Mol Ecol 24:993-1006. doi: $10.1111 /$ mec. 13090

Jha S, Kremen C (2013) Resource diversity and landscape-level homogeneity drive native bee foraging. Proc Natl Acad Sci USA 110:555-558. doi:10.1073/pnas.1208682110

Koch JB, Looney C, Sheppard WS et al (2017) Patterns of population genetic structure and diversity across bumble bee communities in the Pacific Northwest. Conserv Genet. doi:10.1007/ s10592-017-0944-8

Koffler S, de Matos Peixoto Kleinert A, Jaffé R (2017) Quantitative conservation genetics of wild and managed bees. Conserv Genet. doi:10.1007/s10592-016-0904-8

Landaverde-Gon zález P, Enríquez E, Ariza MA et al (2017) Fragmentation in the clouds? The population genetics of the native bee Partamona bilineata (Hymenoptera: Apidae: Meliponini) in the cloud forests of Guatemala. Conserv Genet. doi:10.1007/ s10592-017-0950-x

Lecocq T, Gérard M, Michez D, Dellicour S (2017) Conservation genetics of European bees: new insights from the continental scale. Conserv Genet. doi:10.1007/s10592-016-0917-3

López-Uribe MM, Zamudio KR, Cardoso CF, Danforth BN (2014) Climate, physiological tolerance and sex-biased dispersal shape genetic structure of Neotropical orchid bees. Mol Ecol 23:18741890. doi: $10.1111 / \mathrm{mec} .12689$

López-Uribe MM, Morreale SJ, Santiago CK, Danforth BN (2015) Nest suitability, fine-scale population structure and male-mediated dispersal of a solitary ground nesting bee in an urban landscape. PLoS ONE 10:e0125719. doi:10.1371/journal.pone. 0125719

López-Uribe MM, Cane JH, Minckley RL, Danforth BN (2016) Crop domestication facilitated rapid geographical expansion of a specialist pollinator, the squash bee Peponapis pruinosa. Proc Biol Sci. doi:10.1098/rspb.2016.0443

López-Uribe MM, Appler RH, Youngsteadt E et al (2017) Higher immunocompetence is associated with higher genetic diversity in feral honey bee colonies (Apis mellifera). Conserv Genet. doi:10.1007/s10592-017-0942-x

Lozier JD (2014) Revisiting comparisons of genetic diversity in stable and declining species: assessing genome-wide polymorphism in North American bumble bees using RAD sequencing. Mol Ecol 23:788-801. doi:10.1111/mec.12636

Lozier JD, Zayed A (2016) Bee conservation in the age of genomics. Conserv Genet. doi:10.1007/s10592-016-0893-7

McKendrick L, Provan J, Fitzpatrick U et al (2017) Microsatellite analysis supports the existence of three cryptic species within the bumble bee Bombus lucoroum sensu lato. Conserv Genet. doi:10.1007/s10592-017-0965-3

Ollerton J, Winfree R, Tarrant S (2011) How many flowering plants are pollinated by animals? Oikos 120:321-326. doi:10.1111/j.1600-0706.2010.18644.x

Pope NS, Jha S (2017) Inferring the foraging ranges of social bees from sibling genotypes sampled across discrete locations. Conserv Genet. doi:10.1007/s10592-017-0941-y

Potts SG, Imperatriz-Fonseca V, Ngo HT et al (2016) Safeguarding pollinators and their values to human well-being. Nature 540:220-229. doi:10.1038/nature20588

Roubik DW (1982) Obligate necrophagy in a social bee. Science 217:1059-1060. doi:10.1126/science.217.4564.1059

Schenau E, Jha S (2017) High levels of male diploidy but low levels of genetic structure characterize Bombus vosnesenskii populations across the Western US. Conserv Genet. doi:10.1007/ s10592-016-0900-z

Soro A, Field J, Bridge C et al (2010) Genetic differentiation across the social transition in a socially polymorphic sweat bee, Halictus rubicundus. Mol Ecol 19:3351-3363. doi:10.1111/j.1365-294X.2010.04753.x

Soro A, Quezada-Euan JJG, Theodorou P et al (2017) The population genetics of two orchid bees suggest high dispersal, low diploid male production, and only an effect of island isolation on lowering genetic diversity. Conserv Genet. doi:10.1007/ s10592-016-0912-8

Strange JP, Delaney DA, Tarpy DR et al (2017) Novel microsatellite loci reveal high genetic diversity yet low population structure for alfalfa leafcutting bees in North America. Conserv Genet. doi:10.1007/s10592-017-0943-9

Suni SS (2017) Dispersal of the orchid bee Euglossa imperialis over degraded habitat and intact forest. Conserv Genet. doi:10.1007/s10592-016-0902-x

Suni SS, Scott Z, Averill A, Whiteley A (2017) Population genetics of wild and managed pollinators: Implications for crop pollination and the genetic integrity of wild bees. Conserv Genet doi:10.1007/s10592-017-0955-5

vanEngelsdorp D, Meixner MD (2010) A historical review of managed honey bee populations in Europe and the United States and the factors that may affect them. J Invertebr Pathol 103:S80-S95. doi:10.1016/j.jip.2009.06.011

Whitehorn PR, Tinsley MC, Goulson D (2009) Kin recognition and inbreeding reluctance in bumblebees. Apidologie 40:627-633. doi:10.1051/apido/2009050

Woodard SH, Lozier JD, Goulson D et al (2015) Molecular tools and bumble bees: revealing hidden details of ecology and 
evolution in a model system. Mol Ecol 24:2916-2936. doi: $10.1111 / \mathrm{mec} .13198$

Zayed A (2009) Bee genetics and conservation. Apidologie 40:237262. doi:10.1051/apido/2009026
Zayed A, Packer L (2005) Complementary sex determination substantially increases extinction proneness of haplodiploid populations. Proc Natl Acad Sci USA 102:10742-10746. doi:10.1073/ pnas.0502271102 